\section{Small testes: clinical characteristics and ultrasonographic findings}

\author{
Dal Mo Yang ${ }^{1}$, Hyeon-Il Choi ${ }^{1}$, Hyun Cheol Kim', Sang Won Kim', Sung Kyung Moon², \\ Joo Won Lim² $^{2}$ \\ 'Department of Radiology, Kyung Hee University Hospital at Gangdong, Seoul; ' 2 Department \\ of Radiology, Kyung Hee University Hospital, Seoul, Korea
}

The purpose of this pictorial essay is to describe the ultrasonographic and clinical findings of patients with small testes due to a wide range of causes. We retrospectively reviewed the ultrasonographic and clinical findings of various causes of small testes. We present various causes of small testes on ultrasonography including Klinefelter syndrome, testicular torsion, mumps orchitis, inguinal hernia, cryptorchidism, varicocele, and trauma. On ultrasonography, small testes in patients with testicular torsion, mumps orchitis, and trauma usually showed heterogeneous echogenicity. Atrophic testes were homogeneously hypoechoic in patients with cryptorchidism and inguinal hernia and were isoechoic to the normal testis in patients with varicocele. Klinefelter syndrome patients had small hyperechoic or hypoechoic nodules, but the echogenicity of the remnant portion of the testes was homogeneous. Ultrasonography is helpful for detecting small testes and for the differential diagnosis of the various possible causes of small testes.

Keywords: Testis; Small testes; Testicular atrophy; Ultrasonography; Color Doppler ultrasonography

\section{Introduction}

The normal testis in the postpubertal male is oval shaped, $4-5 \mathrm{~cm}$ long, $3 \mathrm{~cm}$ high, and $2.5 \mathrm{~cm}$ wide. However, testis volume differs according to age and the stage of sexual development. It is also common for each testis to have a different volume.

Abnormally small testes are those that are smaller than the 50th percentile for age [1]. The causes of small testes are either congenital or acquired. Chromosomal abnormalities such as primary and secondary hypogonadism induce testicular underdevelopment [2]. Klinefelter syndrome is the most common cause of primary hypogonadism in men [2]. An acquired cause of small testes is testicular atrophy, which entails a testicular volume reduction of $20 \%$ compared with baseline volume or the normal contralateral testis [1,3]. Testicular atrophy may occur after infarction, inflammation, cryptorchidism, varicocele, or trauma [2]. Testicular atrophy is important for male infertility because it is associated with reduced spermatogenesis and reduced fertility [2].

Ultrasonography is the standard imaging modality for patients with suspected scrotal abnormalities. High-resolution, real-time ultrasonography can accurately detect palpable and non-palpable small testes.

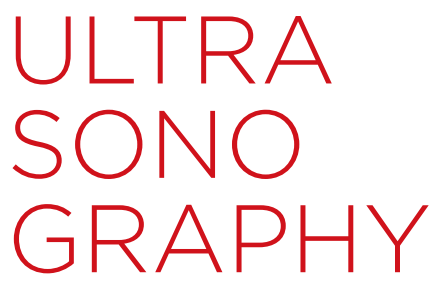

https://doi.org/10.14366/usg.20133 pISSN: 2288-5919 - elSSN: 2288-5943 Ultrasonography 2021;40:455-463

Received: August 22, 2020

Revised: November 1, 2020

Accepted: November 3, 2020

Correspondence to:

Dal Mo Yang, MD, Department of Radiology, Kyung Hee University Hospital at Gangdong, 892 Dongnamro, Gangdong-gu, Seoul 05278, Korea

Tel. +82-2-440-6183

Fax. +82-2-440-6932

E-mail:dmy2988@daum.net
This is an Open Access article distributed under the terms of the Creative Commons Attribution NonCommercial License (http://creativecommons.org/ licenses/by-nc/4.0/) which permits unrestricted noncommercial use, distribution, and reproduction in any medium, provided the original work is properly cited.

Copyright (C) 2021 Korean Society of Ultrasound in Medicine (KSUM)

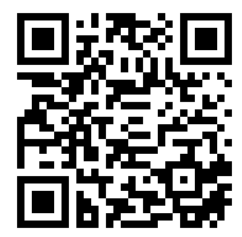

How to cite this article:

Yang DM, Choi HI, Kim HC, Kim SW, Moon SK, Lim JW. Small testes: clinical characteristics and ultrasonographic findings. Ultrasonography. 2021 Jul;40(3):455-463. 
In this study, we reviewed the ultrasonographic and clinical findings of patients with various causes of small testes (Table 1).

\section{Materials and Methods}

We retrospectively reviewed the medical records and ultrasonographic features of patients with various causes of small testes who presented between 2012 and 2019. The diagnosis was based on surgical resection, clinical findings, and ultrasonographic findings. A small testis diagnosis was given for patients with testes smaller than the 50th percentile for their age or whose testicular volume was reduced by $2 \mathrm{~mL}$ or $20 \%$ of their normal contralateral testis $[1,3]$. Grayscale images of the testes were obtained in the transverse and longitudinal planes. Testicular volume was determined as follows: after the maximum length, width, and height were identified on ultrasonography, the actual values were measured and the volume was calculated using the formula for an ellipsoid: volume $=\pi / 6 \times$ length $\times$ width $\times$ height [4]. The echogenicity of small testes was compared with that of the contralateral normal testis.

All ultrasonographic examinations were performed with an iU22 ultrasonography machine (Philips Medical Systems, Bothell, WA, USA) that was equipped with a 5-12 MHz linear array transducer or a LOGIQ 700MR system that was equipped with a $10-5 \mathrm{MHz}$ linear array transducer (GE Healthcare, Milwaukee, WI, USA). Color Doppler ultrasonography was performed with optimized parameters. The power level, threshold, persistence, and wall filter were individually adjusted to maximize blood flow detection throughout the field of view. The speed scale of the color Doppler setting was the lowest detectable flow speed. Color gain control was adjusted so that background color noise was minimal or absent.

Ultrasonographic examinations were performed with the patient in the supine position and with the transducer gently placed on the scrotum. The ultrasonographic images were retrospectively analyzed.

\section{Klinefelter Syndrome}

Klinefelter syndrome is a sex chromosome disorder that results from the presence of a supernumerary $X$ chromosome (karyotype $47, X X Y$ ) [2]. Patients with Klinefelter syndrome have poor Leydig cell function during mid-to-late puberty [5]. Although the underlying mechanism is not known, androgen insufficiency during fetal development has been proposed [5]. Patients with Klinefelter syndrome usually have firm small testes, testicular azoospermia, increased height, female hair distribution, and obesity. They are also at an elevated risk for diabetes mellitus, leukemia, nonseminomatous extragonadal germcell tumors, infertility, and gynecomastia [2]. Klinefelter syndrome is the most common cause of primary hypogonadism in males, and it usually causes small testes [2].

Ultrasonography of patients with Klinefelter syndrome showed small testes that either had a coarse pattern or a heterogeneous echogenicity with hypoechoic and hyperechoic nodules (Figs. 1, 2) [6]. Small intratesticular nodules indicated benign Leydig cell tumors or Leydig cell hyperplasia [6]. Color Doppler ultrasonography revealed high-impedance waveforms with narrow systolic peaks and low diastolic flow of the intratesticular artery [6].

In our two cases, three testes had small hyperechoic or hypoechoic nodules, and all four testes showed homogeneous echogenicity (Figs. 1, 2).

Histopathology typically reveals atrophy with fibrotic, hyalinized seminiferous tubules and Leydig cell hyperplasia [6].

\section{Testicular Torsion}

Testicular torsion results from twisting of the spermatic cord and impairs venous drainage, which subsequently leads to arterial flow impairment and, ultimately, testicular ischemia [2]. The most common predisposing factor is a bell clapper deformity, in which an abnormal insertion of the tunica vaginalis allows broad testis mobility [2].

Ultrasonographic findings vary depending on the duration and degree of spermatic cord rotation. Grayscale images are nonspecific for testicular torsion and often appear normal in the early torsion phases. Testicular swelling and decreased echogenicity are the most commonly encountered findings 4-6 hours after torsion onset [7]. Twenty-four hours after onset, the testes can show heterogeneous echogenicity secondary to vascular congestion, hemorrhage, and infarction [7].

Table 1. Summary of the ultrasonographic and clinical features of small testes

\begin{tabular}{lccc}
\hline \multicolumn{1}{c}{ Type of lesion } & Cause & Clinical feature & Ultrasonographic feature \\
\hline Klinefelter syndrome & Congenital, hypogonadism & Sex chromosome disorder (47, XXY) & Small hyperechoic and/or hypoechoic nodules \\
Testicular torsion & Acquired, vascular compromise & Orchiopexy history & Heterogeneous echogenicity \\
Mumps orchitis & Acquired, vascular compromise & Parotitis, young age & Heterogeneous echogenicity \\
Inguinal hernia & Acquired, vascular compromise & Inguinal mass & Homogeneously hypoechoic \\
Cryptorchidism & Acquired, higher scrotal temperature & Absence of testis in scrotum & Homogeneously hypoechoic \\
Varicocele & Acquired, higher scrotal temperature & More frequent on left side & Isoechoic to the normal testis \\
Trauma & Acquired, testicular rupture or ischemia & Trauma history & Heterogeneous echogenicity \\
\hline
\end{tabular}




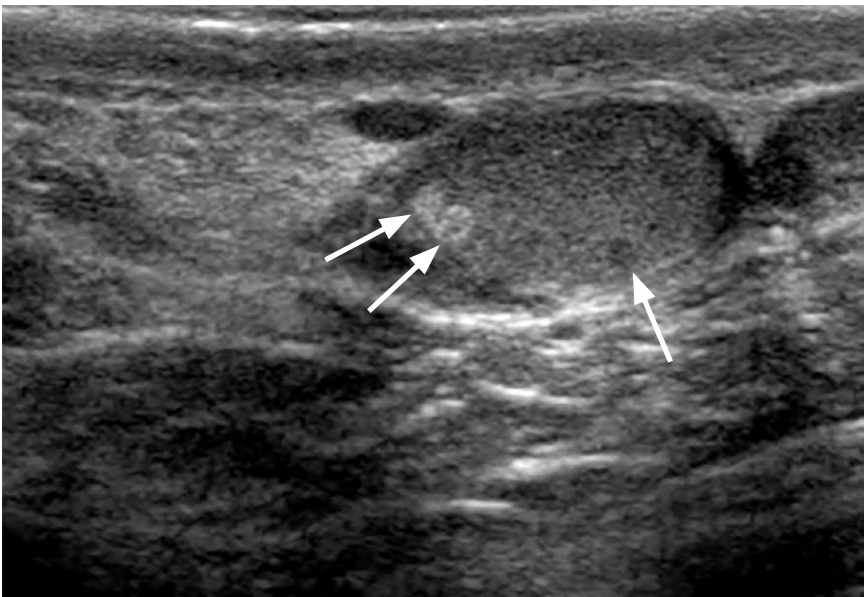

A

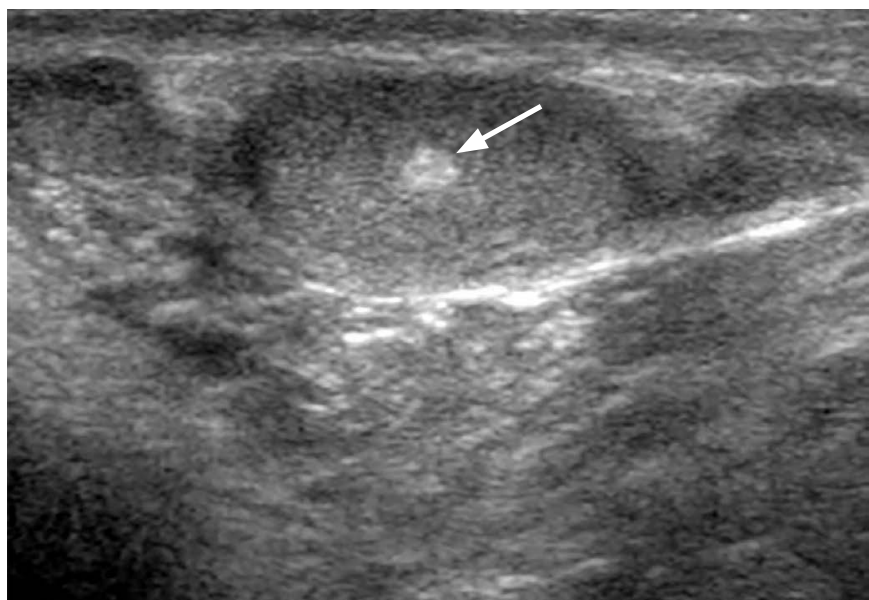

B

Fig. 1. A 28-year-old man with Klinefelter syndrome.

A. Longitudinal ultrasonography shows a small right testis $(0.5 \mathrm{~mL})$ with two small hyperechoic lesions and a hypoechoic lesion in the testis (arrows). B. Longitudinal ultrasonography shows a small left testis $(0.5 \mathrm{~mL}$ ) with a small hyperechoic lesion (arrow).

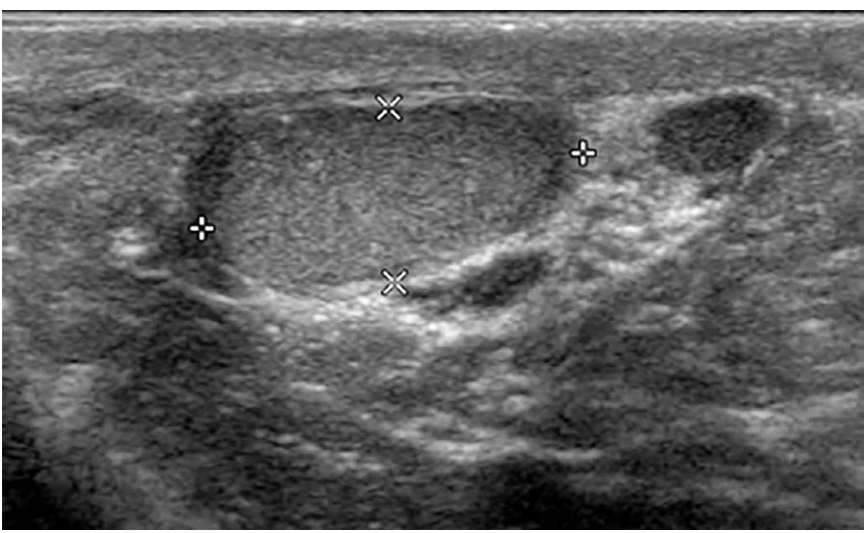

A

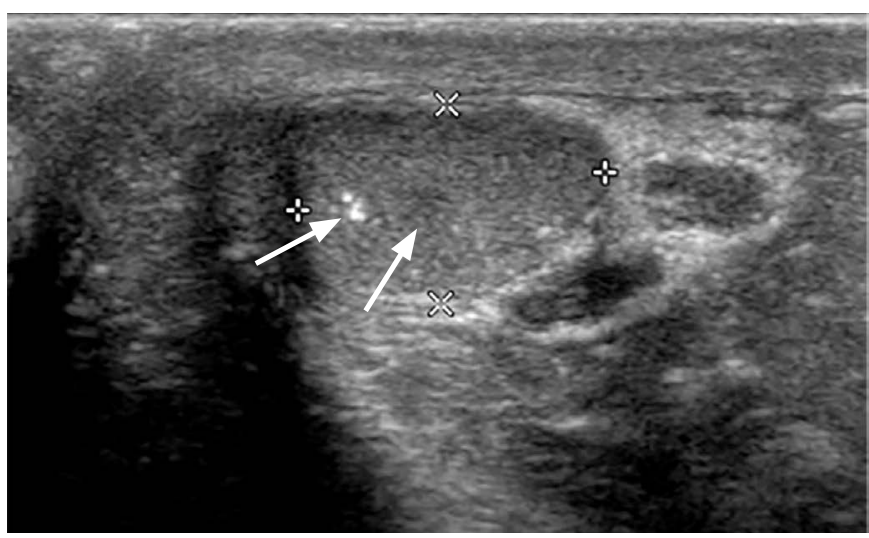

B

Fig. 2. A 29-year-old man with Klinefelter syndrome.

A. Longitudinal ultrasonography shows a small right testis with normal echogenicity and a $0.4-\mathrm{mL}$ testicular volume. B. Longitudinal ultrasonography shows a small left testis $(0.5 \mathrm{~mL})$ with internal hypoechoic and hyperechoic lesions (arrows).

Testicular atrophy is a significant complication of testicular torsion. The preoperative risk factors associated with future testicular atrophy are pain duration for 12 hours or more, heterogeneous echogenicity of testicular parenchyma, and red scrotal skin [8]. In a prior study, all patients whose testes had a sudden blackened or hemorrhagic appearance 5 minutes after detorsion had more than $80 \%$ volume loss [8]. In one of our cases, testis size after torsion gradually decreased and revealed heterogeneous echogenicity on follow-up ultrasonography (Fig. 3).

\section{Mumps Orchitis}

Mumps orchitis is a rare complication occurring in 15\%-30\% of postpubertal male patients with a mumps infection [9].
Grayscale ultrasonographic examinations of patients with mumps orchitis showed swelling and heterogeneous hypoechogenicity of the testes and scrotal wall thickening (Fig. 4A) [10]. Color Doppler ultrasonography showed increased blood flow in the testicular parenchyma of the affected testes (Fig. 4B) [10].

The mumps virus damages testicular tissue as a result of parenchymal edema. The increased pressure caused by parenchymal edema can induce seminiferous tubule necrosis and atrophy of the germinal epithelium [11]. Consequently, testicular atrophy develops in $40 \%-70 \%$ of affected testicles [11].

The ultrasonographic findings of testicular atrophy after mumps orchitis showed heterogeneous low echogenicity with multiple hyperechoic islands and decreased vascularity (Fig. 4C). The 
multiple hyperechoic islands may be remnants of normal testicular parenchyma between layers of ischemic testicular parenchyma (Fig. 4C) [11].

\section{Inguinal Hernia}

Extrinsic compression of the testicular parenchyma or spermatic cord by an inguinal hernia or a hydrocele can compromise testicular blood supply [2]. Excessive compression of the testicular vessels by a large inguinal hernia over a long time can cause testicular atrophy [12], which is a rare complication that occurs in $0.01 \%-1.2 \%$ of inguinal hernias [13].

In one of the cases that we analyzed, echogenicity of the atrophic left testis was induced by an inguinal hernia, and the atrophic left testis was hypoechoic compared with the contralateral normal right testis (Fig. 5).

\section{Cryptorchidism (Undescended Testes)}

Failure of the intra-abdominal testes to descend into the scrotal sac is known as cryptorchidism. Cryptorchidism is the most frequent congenital abnormality of male genitalia, with a prevalence of $2 \%$ $5 \%$ at birth and $1 \%-2 \%$ by 3 months [2]. The testes can be seen in the inguinal canal in $72 \%$ of cases, in a prescrotal location in $20 \%$ of cases, and in an abdominal location in $8 \%$ of cases [2]. The histopathological findings of cryptorchidism include decreased germ-cell counts, spermatogenesis failure, Leydig cell hypoplasia, and testicular fibrosis [14]. Testicular volume in patients with cryptorchidism is lower than that of patients with descended testes [15]. Although the causes of growth and development disturbance in cryptorchid testes have not been established, one suggested cause is exposure to an abnormally high-temperature environment

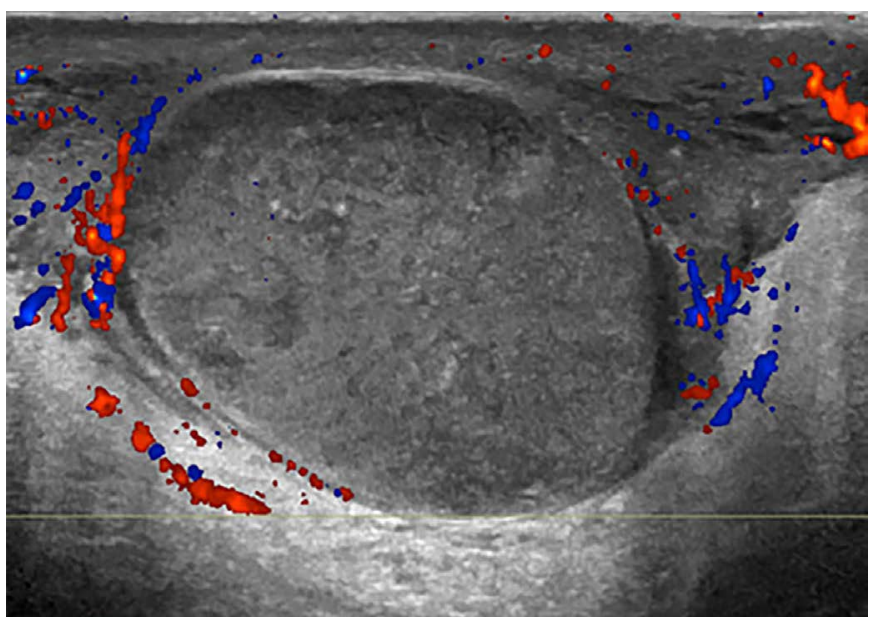

A

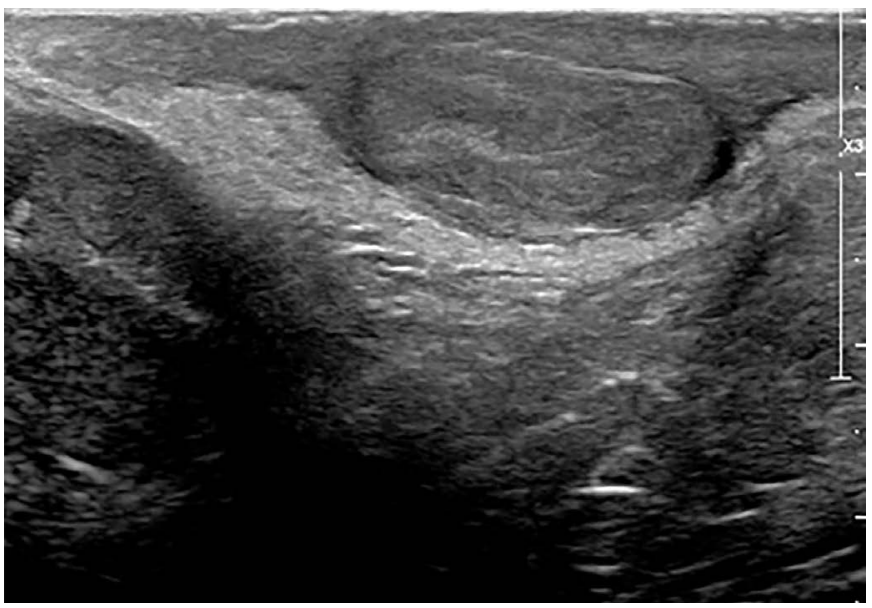

C

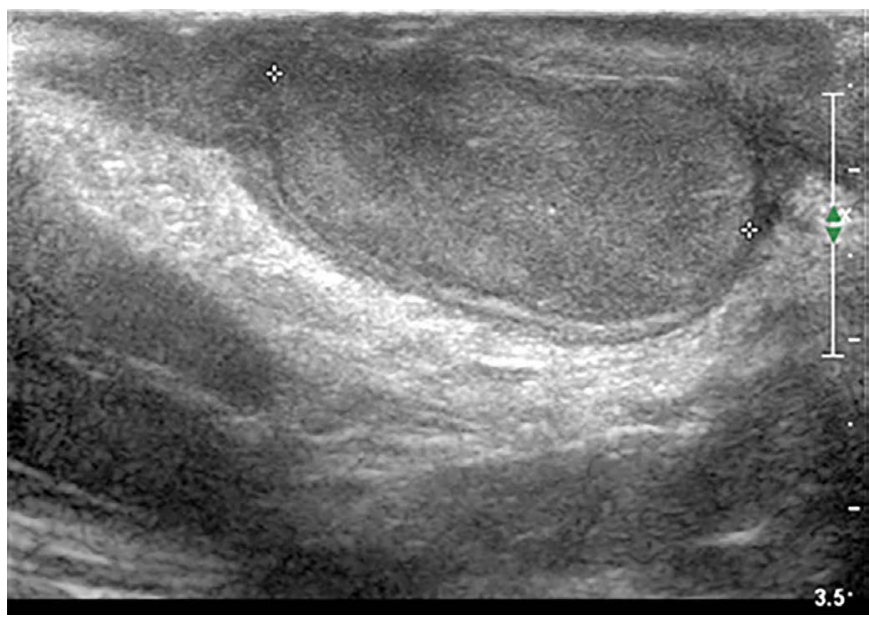

B

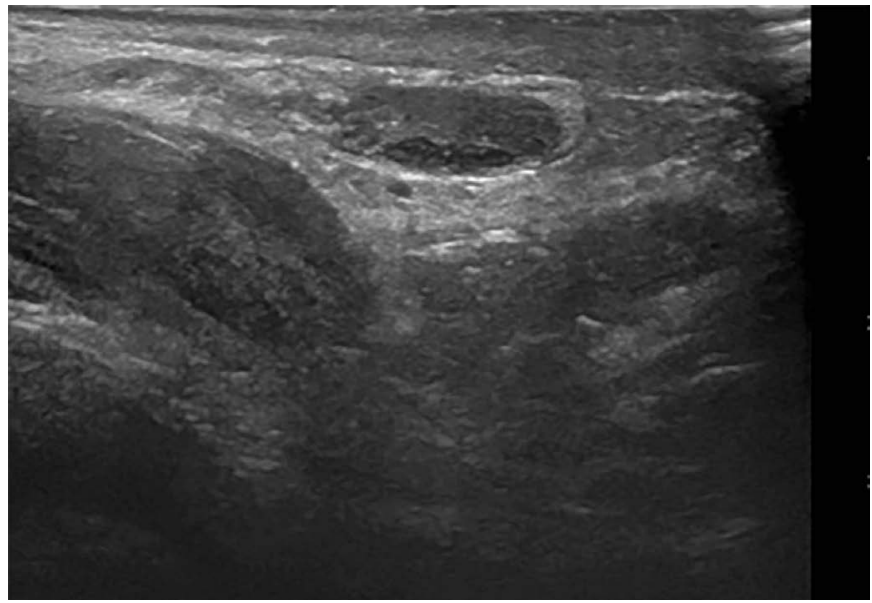

D

Fig. 3. A 14-year-old boy with left testicular torsion with orchiopexy.

A. Longitudinal color Doppler ultrasonography shows no blood flow in the enlarged left testis with heterogeneously low echogenicity and a 10.1 -mL testicular volume. B-D. Follow-up longitudinal ultrasonography after orchiopexy demonstrates a gradual decrease in the volume of the left testis, showing heterogeneous echogenicity (B, 18 days later; $C, 64$ days; $D, 134$ days). 
[14]. More proximally located cryptorchid testes have been shown to have lower volumes due to higher-temperature environments [14].

In the two cryptorchidism cases that we analyzed, the affected testis had a lower volume and was less echogenic on ultrasonography than the contralateral testis (Fig. 6) [15]. Ultrasonographic elastography is a simple noninvasive method for measuring tissue elasticity [16]. Patients with cryptorchidism present higher testicular stiffness than is found in normal testes due to increased intertubular fibrosis and testicular atrophy [16].

\section{Varicocele}

A varicocele is an abnormal dilatation of the pampiniform plexus, which drains the testes. The prevalence of varicocele in the general population ranges from $15 \%$ to $20 \%$ [7]. Varicoceles are found more commonly on the left side or bilaterally than on the right side alone. Because the left testicular vein drains into the left renal vein at a perpendicular angle, rather than directly into the inferior vena cava, the left testicular vein is exposed to high pressure from the left renal vein [2]. The reversal of venous flow is seen in cases of absent or incomplete valves.

Ultrasonography showed increases in venous diameter of $\geq 3 \mathrm{~mm}$ during the Valsalva maneuver [2]. The high volume of venous reflux causes an increase in testicular temperature and leads to impaired spermatogenesis and testicular atrophy [17]. In one of our cases, the echogenicity of the atrophic left testis affected by varicocele was similar to that of the contralateral normal right testis (Fig. 7).

Adolescents with volume differences greater than $10 \%$ between the normal and affected testes on ultrasonography have a higher risk of future infertility [17]. In adolescents with varicocele who have abnormal semen parameters, treatment is recommended to prevent

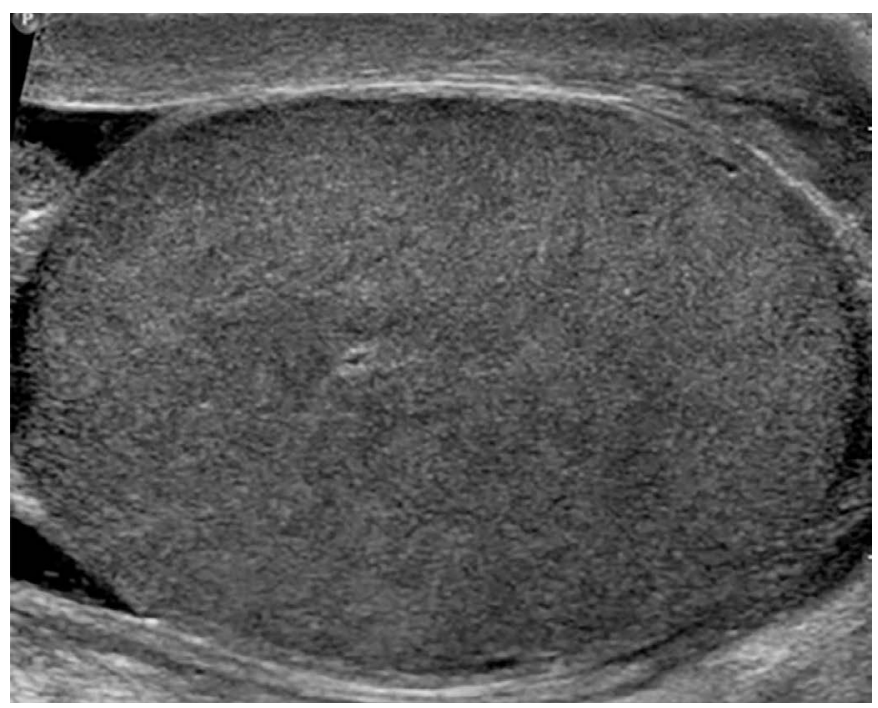

A

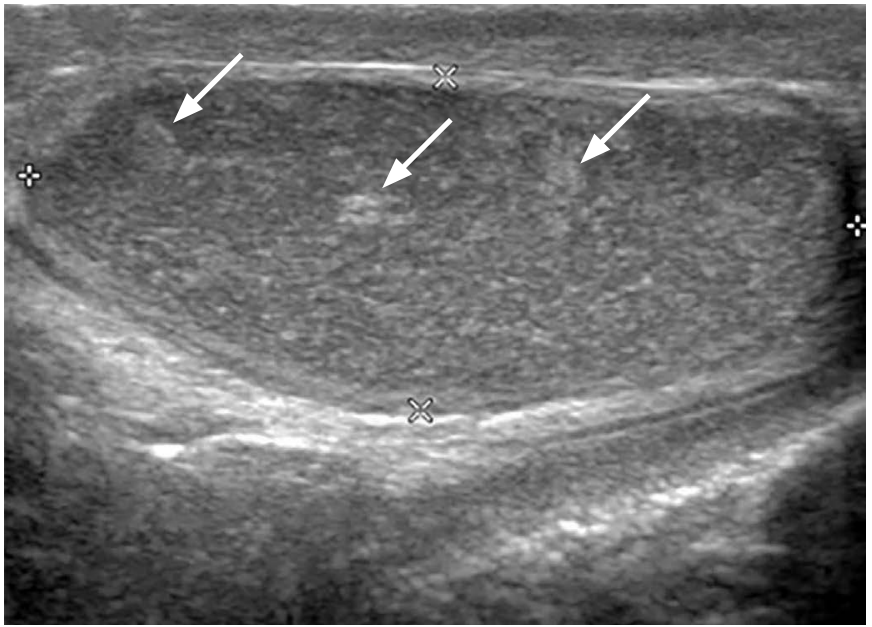

C

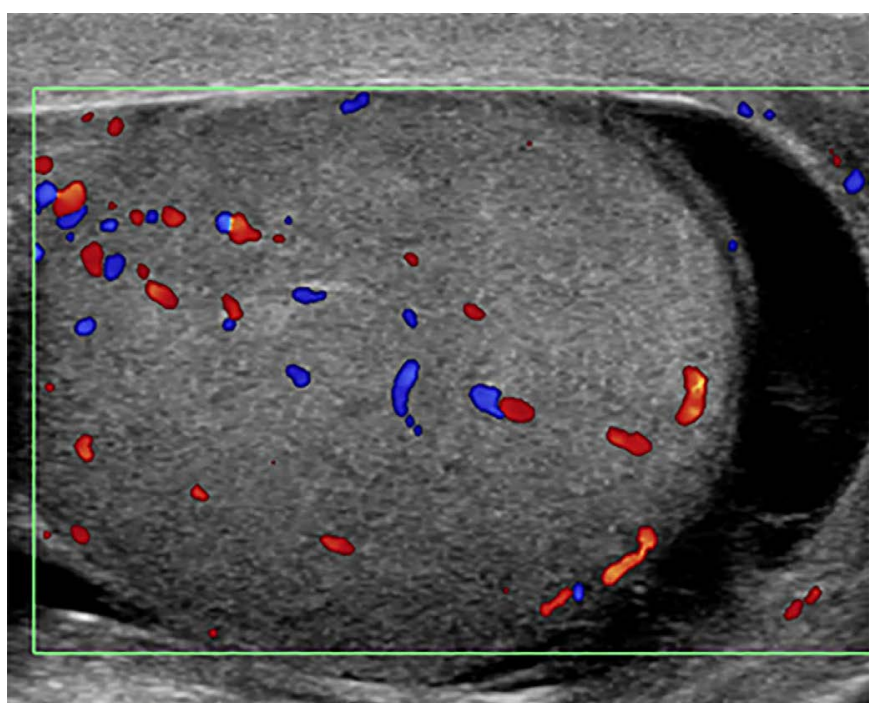

B

Fig. 4. A 16-year-old boy with mumps orchitis.

A. Longitudinal ultrasonography shows an enlarged hypoechoic right testis with a $35-\mathrm{mL}$ testicular volume. B. Color Doppler ultrasonography shows increased blood flow in the enlarged testis. C. After 110 days, longitudinal ultrasonography shows a right testis with reduced volume of $5.2 \mathrm{~mL}$. The testis is heterogeneously hypoechoic with multiple hyperechoic foci (arrows) on ultrasonography. 


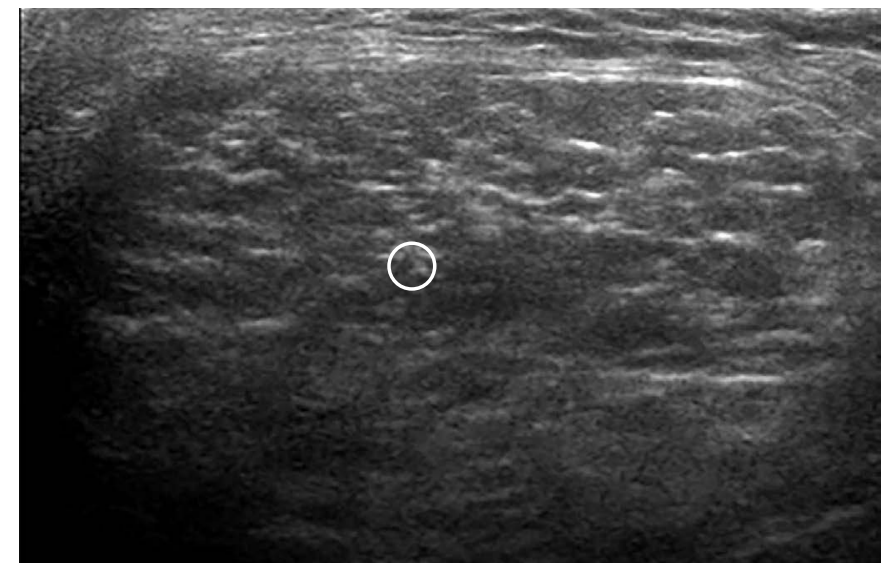

A

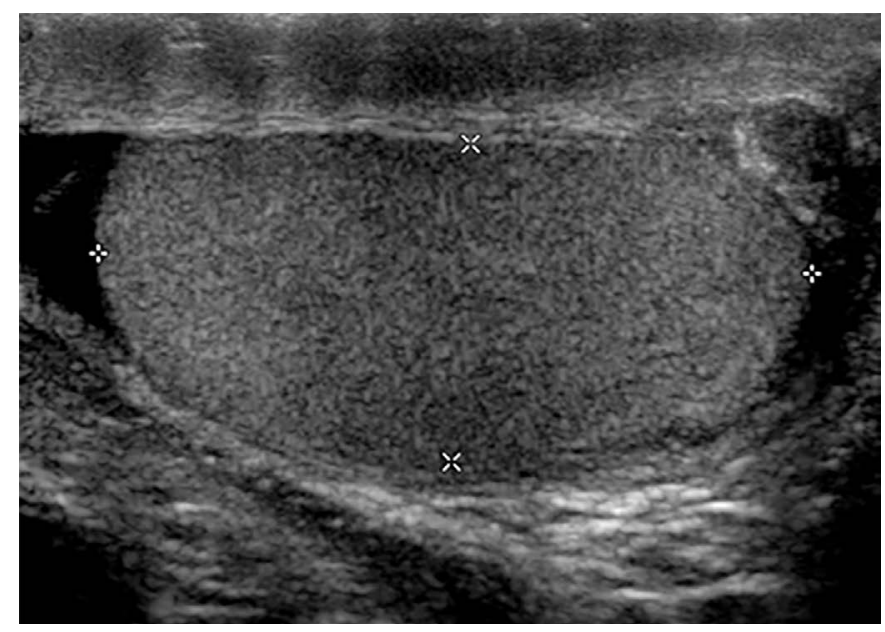

C

Fig. 5. A 31-year-old man with left inguinal hernia.

A. Longitudinal ultrasonography shows herniated omental fat presenting as a heterogeneously hyperechoic mass in the left inguinal canal. B, C. Longitudinal ultrasonography shows a small hypoechoic left testis. D. Longitudinal ultrasonography shows a normal right testis. Circles indicate omental fat.

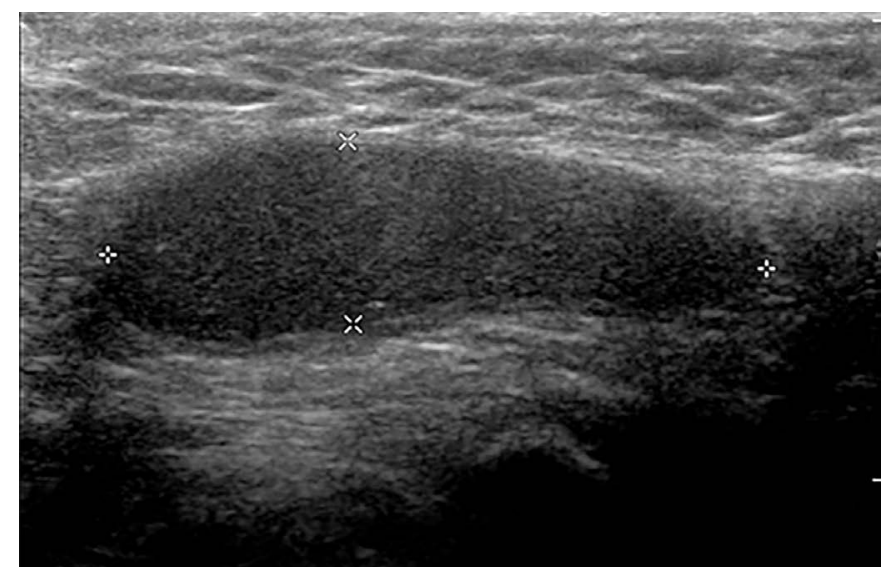

A

Fig. 6. A 19-year-old man with right cryptorchidism.

A. Longitudinal ultrasonography shows a small, hypoechoic right testis in the right inguinal canal. B. Longitudinal ultrasonography shows a normal left testis.

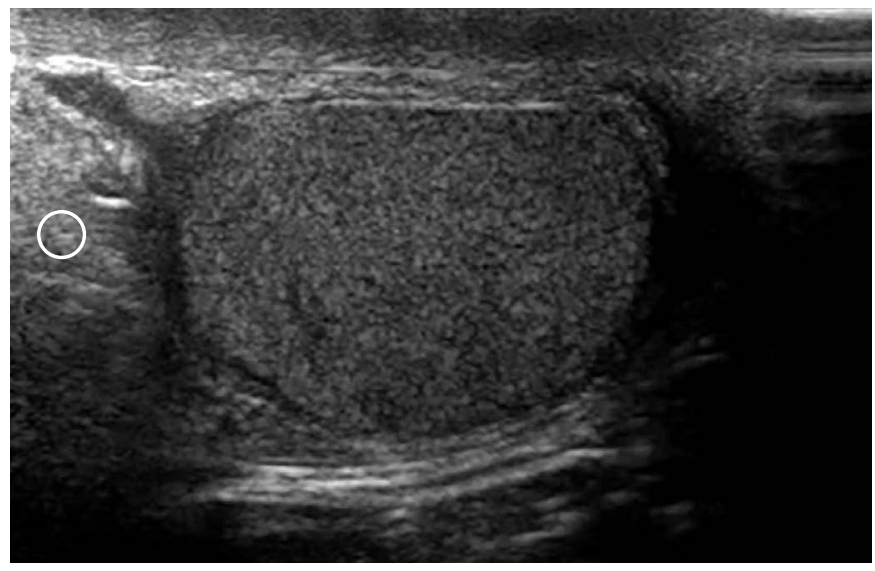

B

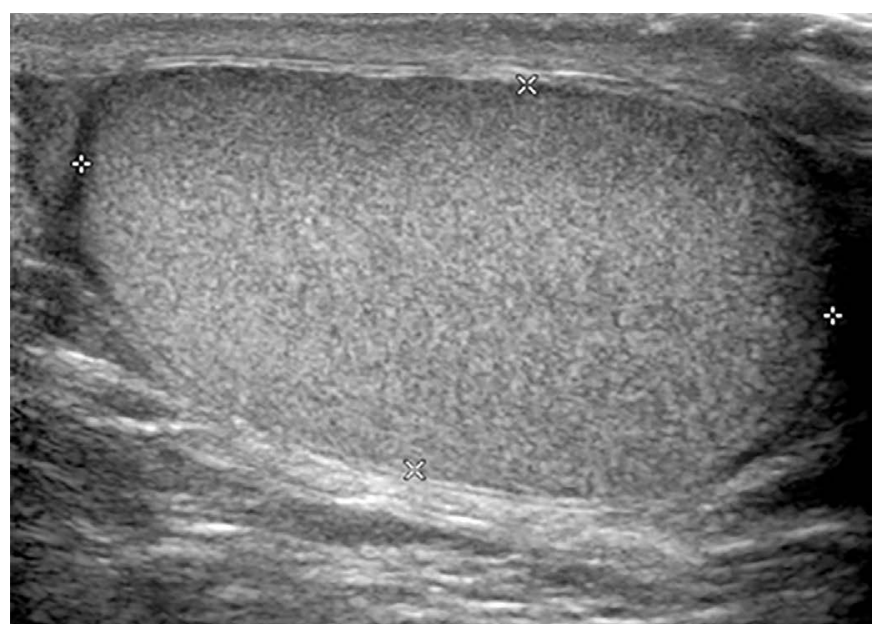

D 
testicular growth arrest and infertility [18]. Varicocelectomy has been shown to increase left testicular volume [19].

\section{Trauma}

Testicular trauma is not uncommon and typically results from a motor vehicle accident, an athletic injury, a direct blow, or a straddle injury. Trauma can result in contusion, hematoma, fracture, or testis rupture [7].

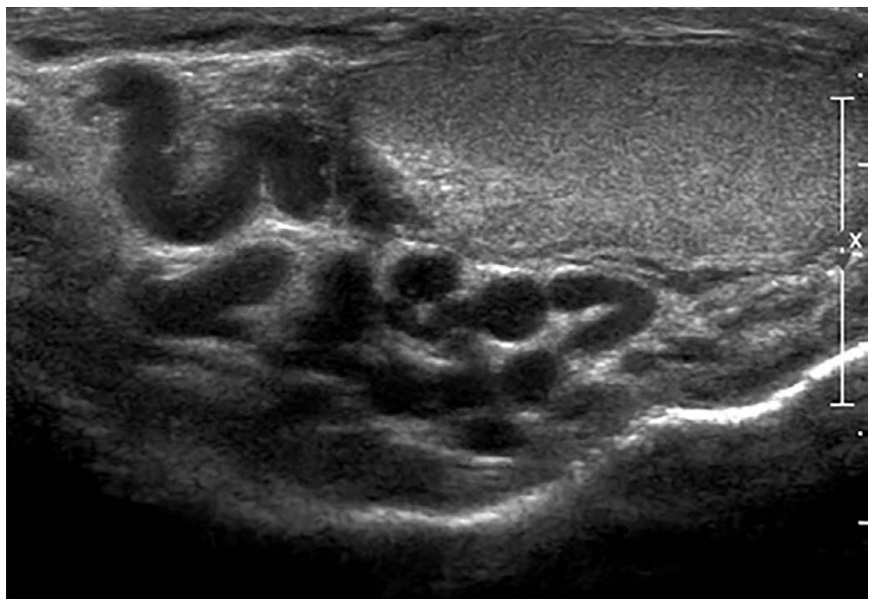

A
The ultrasonographic findings in cases of testicular rupture usually include an interruption to the tunica albuginea, heterogeneous testes with one testis having irregular poorly defined borders, scrotal wall thickening, and a large hematocele [7]. Heterogeneous intratesticular lesions are caused by hemorrhage or infarction [7]. Color Doppler ultrasonography is helpful because it can reveal abnormal capsular blood flow to the testes.

Scrotal trauma may lead to ischemia of viable parenchyma due

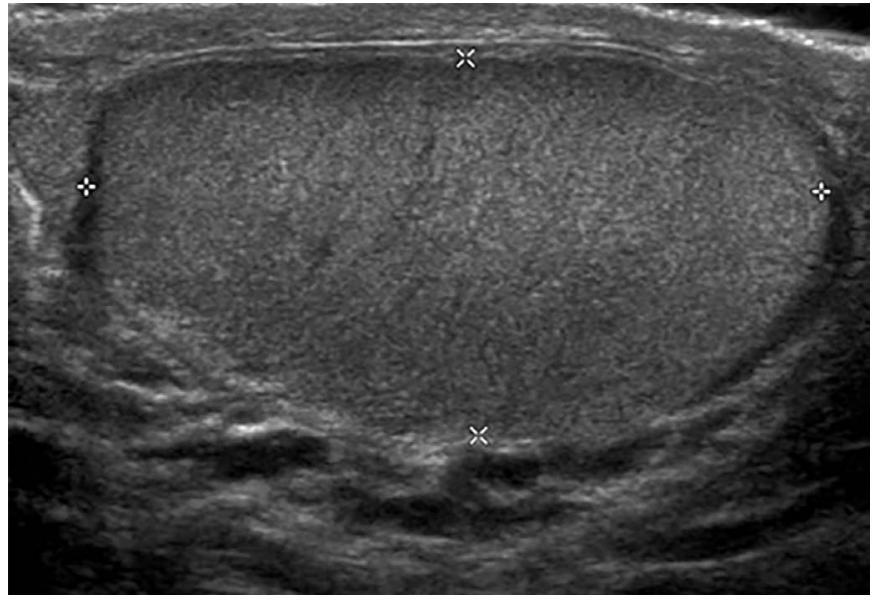

B

Fig. 7. A 55-year-old man with varicocele.

A, B. Longitudinal ultrasonography shows that the left testis $(A)$ is smaller $(7.4 \mathrm{~mL})$ than the right testis $(11.2 \mathrm{~mL})(B)$. There are multiple anechoic structures in the supratesticular region of the left testis.

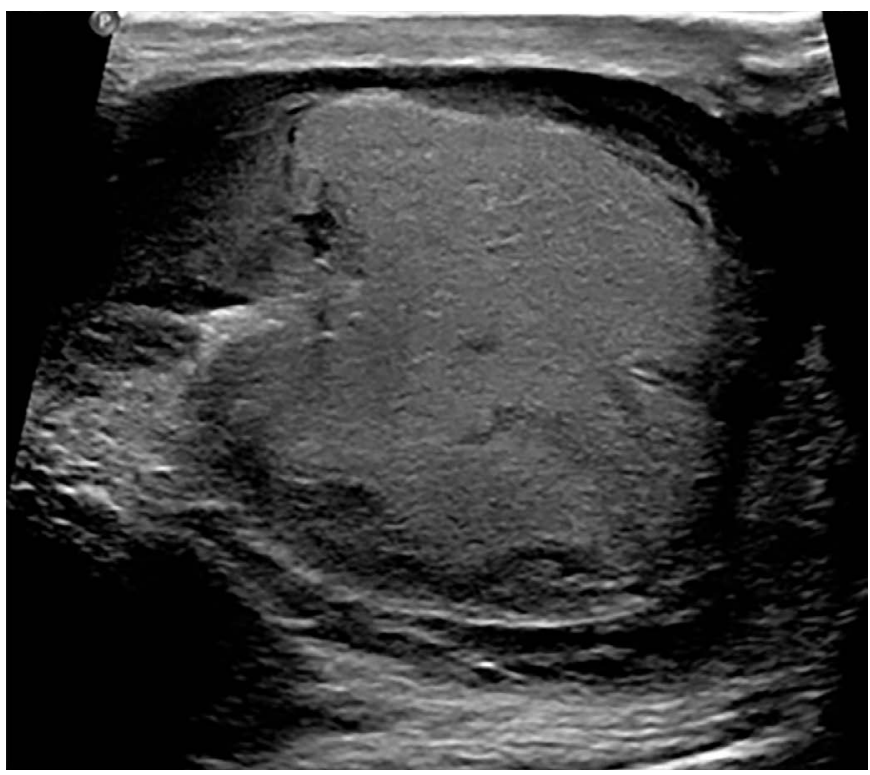

A

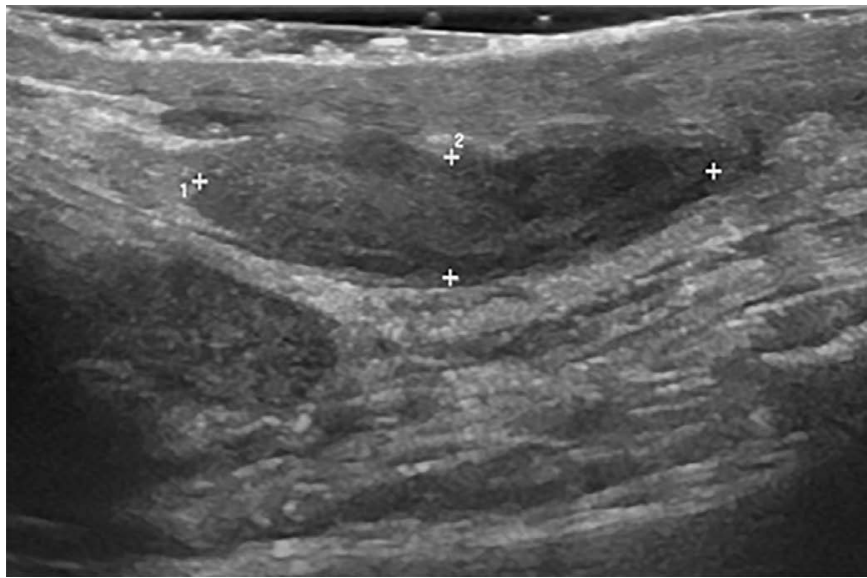

B

Fig. 8. A 28-year-old man with a right testicular contusion from trauma.

A. Longitudinal ultrasonography shows an enlarged, heterogeneously hypoechoic right testis with a 12-mL testicular volume. B. After 173 days, longitudinal ultrasonography shows a right testis reduced in volume (to $2.6 \mathrm{~mL}$ ) with an oblong shape. The testis is heterogeneously hypoechoic on ultrasonography. 
to increased intratesticular pressure, while resorption of necrotic testicular tissue leads to testicular atrophy [20]. Cross et al. [20] reported that $60 \%$ of atrophic testes after trauma showed homogeneous echogenicity on ultrasonography, while $40 \%$ of atrophic testes showed heterogeneous echogenicity and reduced blood flow on color Doppler ultrasonography.

In the trauma case we analyzed, the atrophic testis was heterogeneously hypoechoic (Fig. 8).

\section{Conclusion}

A wide range of conditions are associated with small testes, and radiologists should be aware of the variety of causes of this condition because ultrasonographic findings differ according to the underlying cause. Small testes in patients who experienced testicular torsion, mumps orchitis, or trauma usually showed heterogeneous echogenicity on ultrasonography. Relative to the normal testis, atrophic testes were homogeneously hypoechoic in patients with cryptorchidism and inguinal hernia and were isoechoic in patients with varicocele. Interestingly, most testes of Klinefelter syndrome patients had small hyperechoic or hypoechoic nodules, but the echogenicity of the remnant portion of the testes was homogeneous.

We suggest that heterogeneous echogenicity in small testes is due to testicular necrosis and hemorrhage caused by severe vascular compromise or trauma, such as testicular torsion, mumps orchitis, or other types of trauma. Homogeneous echogenicity in small testes is related to a lower degree of vascular compromise by extrinsic compression of the spermatic cord or testicular parenchyma in inguinal hernia cases and spermatogenesis failure resulting from elevated testicular temperatures in cases of cryptorchidism and varicocele.

ORCID: Dal Mo Yang: https://orcid.org/0000-0001-7766-5826; Hyeon-II Choi: https:// orcid.org/0000-0002-8739-7965; Hyun Cheol Kim: https://orcid.org/0000-00023121-092X; Sang Won Kim: https://orcid.org/0000-0002-1999-9163; Sung Kyung Moon: https://orcid.org/0000-0003-4831-3439; Joo Won Lim: https://orcid.org/00000002-7989-3408

\section{Author Contributions}

Conceptualization: Yang DM. Data acquisition: Yang DM, Kim HC, Kim SW, Moon SK, Lim JW. Data analysis or interpretation: Yang DM, Choi HI. Drafting of the manuscript: Yang DM, Kim HC, Kim SW, Choi HI. Critical revision of the manuscript: Yang DM, Moon SK, Lim JW, Choi HI. Approval of the final version of the manuscript: all authors.

\section{Conflict of Interest}

No potential conflict of interest relevant to this article was reported.

\section{References}

1. Abdelhalim A, Chamberlin JD, Young I, Fahim M, Chuang KW, McAleer IM, et al. Testicular volume changes in laparoscopic staged Fowler-Stephens orchiopexy: studying the impact of testicular vessel division. Urology 2019;127:113-118.

2. Mittal PK, Little B, Harri PA, Miller FH, Alexander LF, Kalb B, et al. Role of imaging in the evaluation of male infertility. Radiographics 2017;37:837-854.

3. Lee JW, Lee TY, Choi HY. Change of the testicular volume after mumps orchitis. Korean J Urol 2007;48:542-547.

4. Paltiel HJ, Diamond DA, Di Canzio J, Zurakowski D, Borer JG, Atala A. Testicular volume: comparison of orchidometer and US measurements in dogs. Radiology 2002;222:114-119.

5. Rodprasert W, Virtanen HE, Makela JA, Toppari J. Hypogonadism and cryptorchidism. Front Endocrinol (Lausanne) 2019;10:906.

6. Rocher L, Moya L, Correas JM, Mutuon P, Ferlicot S, Young J, et al. Testis ultrasound in Klinefelter syndrome infertile men: making the diagnosis and avoiding inappropriate management. Abdom Radiol (NY) 2016;41:1596-1603.

7. Dogra VS, Gottlieb RH, Oka M, Rubens DJ. Sonography of the scrotum. Radiology 2003;227:18-36.

8. Grimsby GM, Schlomer BJ, Menon VS, Ostrov L, Keays M, Sheth KR, et al. Prospective evaluation of predictors of testis atrophy after surgery for testis torsion in children. Urology 2018;116:150-155.

9. Hviid A, Rubin S, Muhlemann K. Mumps. Lancet 2008;371:932944.

10. Park SJ, Kim HC, Lim JW, Moon SK, Ahn SE. Distribution of epididymal involvement in mumps epididymo-orchitis. J Ultrasound Med 2015;34:1083-1089.

11. Choi HI, Yang DM, Kim HC, Kim SW, Jeong HS, Moon SK, et al. Testicular atrophy after mumps orchitis: ultrasonographic findings. Ultrasonography 2020;39:266-271.

12. Salemis NS, Nisotakis K. Testicular atrophy secondary to a large long standing incarcerated inguinal hernia. Clin Pract 2011;1:e68.

13. Sonderman KA, Wolf LL, Armstrong LB, Taylor K, Jiang W, Weil BR, et al. Testicular atrophy following inguinal hernia repair in children. Pediatr Surg Int 2018;34:553-560.

14. Zvizdic Z, Milisic E, Halimic A, Zvizdic D, Zubovic SV. Testicular volume and testicular atrophy index as predictors of functionality of unilaterally cryptorchid testis. Med Arch 2014;68:79-82.

15. van der Plas EM, Zijp GW, Froeling FM, van der Voort-Doedens LM, Meii-de Vries A, Goede J, et al. Long-term testicular volume after orchiopexy at diagnosis of acquired undescended testis. J Urol 2013; 190:257-262.

16. Shin HJ, Lee YS, Yoon H, Kim MJ, Han SW, Kim HY, et al. Testicular volume and elasticity changes in young children with undescended testes. Med Ultrason 2017;19:380-385.

17. Paduch DA, Niedzielski J. Repair versus observation in adolescent 
varicocele: a prospective study. J Urol 1997;158:1128-1132.

18. Diamond DA, Zurakowski D, Bauer SB, Borer JG, Peters CA, Cilento $B G \mathrm{Jr}$, et al. Relationship of varicocele grade and testicular hypotrophy to semen parameters in adolescents. J Urol 2007;178:1584-1588.
19. Laven JS, Haans LC, Mali WP, te Velde ER, Wensing CJ, Eimers JM. Effects of varicocele treatment in adolescents: a randomized study. Fertil Steril 1992;58:756-762.

20. Cross JJ, Berman LH, Elliott PG, Irving S. Scrotal trauma: a cause of testicular atrophy. Clin Radiol 1999;54:317-320. 